JOURNAL CLUB

\title{
SPLUNC1: link between acidity and dehydration of the airway surface liquid in CF
}

Short palate lung and nasal epithelial clone 1 (SPLUNC1) is the most abundant secreted protein in the airways and helps maintain a normal airway surface liquid (ASL) volume through its regulation of the epithelial $\mathrm{Na}^{+}$channel $(\mathrm{ENaC})$. In cystic fibrosis (CF), it has been proposed that increased $\mathrm{Na}^{+}$absorption by ENaC contributes to ASL depletion, despite the presence of SPLUNC1.

The study by Garland et al showed the $\mathrm{pH}$ of nasal secretions from CF subjects ( $\mathrm{pH}$ 6.5) was more acidic than non-CF subjects ( $\mathrm{pH} 7$ 7.2), consistent with previous studies of CF ASL. Re-creating such conditions in vitro, the investigators found that alkalinising the ASL across CF airway epithelial cultures prevented fluid hyperabsorption, an effect absent in SPLUNC1-depleted cultures. SPLUNC1 binding to the cell surface, which was dependent on $\mathrm{ENaC}$ expression, was reduced under acidic conditions. The authors reasoned the acidity of the CF airways may alter the ability of SPLUNC1 to bind to ENaC, explaining why it is unable to limit $\mathrm{ENaC}$ activity in $\mathrm{CF}$. This hypothesis was supported by demonstrating that deletion of two $\mathrm{pH}$-sensitive salt bridges in the SPLUNC1 protein rendered SPLUNC1 binding at the cell surface $\mathrm{pH}$-insensitive, restoring normal $\mathrm{ENaC}$ regulation and ASL volume under acidic conditions.

In addition to identifying the $\mathrm{pH}$-dependent activity of SPLUNC1 as an important link between the acidity of the $\mathrm{CF}$ airways and the dysregulation of $\mathrm{ENaC}$, the study may also provide evidence of how the cystic fibrosis transmembrane conductance regulator (CFTR) indirectly regulates $\mathrm{ENaC}$ activity, since aberrant CFTR-dependent $\mathrm{HCO}_{3}^{-}$secretion is proposed to contribute to the acidity of the CF ASL. Raising CF ASL pH could restore normal mucosal hydration, as well as other vital $\mathrm{pH}$-dependent processes such as bacterial killing by antimicrobials, and thus warrants further investigation as a potential avenue for CF therapy.

- Garland AL, Walton WG, Coakley RD, et al. Molecular basis for pH-dependent mucosal dehydration in cystic fibrosis airways. Proc Natl Acad Sci USA 2013;110:15973-8.

\section{James P Garnett}

Correspondence to Dr James P Garnett, Division of Biomedical Sciences, St George's, University of London, Cranmer Terrace, Tooting, London SW170RE, UK; jgarnett@sgul.ac.uk

Competing interests None.

Provenance and peer review Not commissioned; internally peer reviewed.

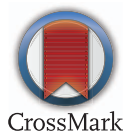

To cite Garnett JP. Thorax 2014;69:1004.

Published Online First 1 November 2013

Thorax 2014;69:1004. doi:10.1136/thoraxjnl-2013-204665 